Research Article

\title{
Pharmacokinetic Effects of $L$-Tetrahydropalmatine on Ketamine in Rat Plasma by Ultraperformance Liquid Chromatography Tandem Mass Spectrometry
}

\author{
Yan Du $\mathbb{D}^{1,2}$ Hongliang Su, ${ }^{3}$ Jie Cao, ${ }^{3}$ Zhiwen Wei, ${ }^{3}$ Yujin Wang $\mathbb{D}^{3},{ }^{3}$ and Keming Yun $\mathbb{D}^{3}$ \\ ${ }^{1}$ School of Pharmaceutical Science, Shanxi Medical University, Taiyuan, 030001 Shanxi, China \\ ${ }^{2}$ School of Pharmacy, University of Maryland Baltimore, Baltimore, 21201 MD, USA \\ ${ }^{3}$ School of Forensic Medicine, Shanxi Medical University, Taiyuan, 030001 Shanxi, China
}

Correspondence should be addressed to Yan Du; dulinhui-2004@163.com, Yujin Wang; cxddy_2004@sxmu.edu.cn, and Keming Yun; yunkeming5142@163.com

Received 7 January 2020; Revised 16 April 2020; Accepted 13 June 2020; Published 7 July 2020

Academic Editor: Hugh D. Smyth

Copyright ( 2020 Yan Du et al. This is an open access article distributed under the Creative Commons Attribution License, which permits unrestricted use, distribution, and reproduction in any medium, provided the original work is properly cited.

\begin{abstract}
Male Sprague-Dawley rats $(n=18)$ were randomly divided into three groups: a saline group $(20 \mathrm{~mL} / \mathrm{kg}$ by gavage), a ketamine (KET) group $(100 \mathrm{mg} / \mathrm{kg}$ by gavage), and a KET (the same routes and doses) combined with levo-tetrahydropalmatine ( $L$-THP; $40 \mathrm{mg} / \mathrm{kg}$ by gavage) group $(n=6)$. Blood samples were acquired at different time points after drug administration. A simple and sensitive ultraperformance liquid chromatography tandem mass spectrometry (UPLC-MS/MS) method was established to determine the concentrations of KET and its metabolite, norketamine (NK), in rat plasma. Chromatographic separation was achieved using a BEH C18 column $(2.1 \mathrm{~mm} \times 50 \mathrm{~mm}, 1.7 \mu \mathrm{m})$ with chlorpheniramine maleate (Chlor-Trimeton) as an internal standard (IS). The initial mobile phase consisted of acetonitrile-water with $0.1 \%$ methanoic acid $(80: 20, v / v)$. The multiple reaction monitoring $(\mathrm{MRM})$ modes of $\mathrm{m} / \mathrm{z} 238.1 \rightarrow \mathrm{m} / \mathrm{z} 179.1$ for KET, $\mathrm{m} / \mathrm{z} 224.1 \rightarrow \mathrm{m} / \mathrm{z} 207.1$ for NK, and $\mathrm{m} / \mathrm{z} 275 \rightarrow \mathrm{m} / \mathrm{z} 230$ for Chlor-Trimeton (IS) were utilized to conduct a quantitative analysis. Calibration curves of KET and NK in rat plasma demonstrated good linearity in the range of $2.5-500 \mathrm{ng} / \mathrm{mL}(r>0.9994)$, and the lower limit of quantification (LLOQ) was $2.5 \mathrm{ng} / \mathrm{mL}$ for both. Moreover, the intra- and interday precision relative standard deviation (RSD) of KET and NK were less than $4.31 \%$ and $6.53 \%$, respectively. The accuracies (relative error) of KET and NK were below $-1.41 \%$ and $-6.07 \%$, respectively. The extraction recoveries of KET and NK were more than $81.23 \pm 3.45 \%$ and $80.42 \pm 4.57 \%$, respectively. This sensitive, rapid, and selective UPLC-MS/MS method was successfully applied to study the pharmacokinetic effects of $L$-THP on KET after gastric gavage. The results demonstrated that ${ }_{\text {-THP }}$ could increase the bioavailability of KET and promote the metabolism of KET. The results showed that $L$-THP has pharmacokinetics effects on KET in rat plasma.
\end{abstract}

\section{Introduction}

Ketamine (KET), originally used as a surgical anesthetic, became a popular street drug in the USA in the 1970s. KET abuse has spread over North America and Europe and has also affected China in recent years [1]. Based on its dissociative anesthetic properties, KET generates visual and auditory distortions and a sense of floating and dissociation in abusers [2]. The main metabolic pathway involves $\mathrm{N}$-demethylation of KET by cytochrome (CYP) 4503A to form the active metabolite, norketamine (NK) [3].
Levo-tetrahydropalmatine (L-THP), an alkaloid isolated from the traditional Chinese herbal medicine Corydalis and Stephania, has been widely used in many traditional Chinese herbal preparations for around 40 years [4]. As a nonopioid analgesic, $L$-THP has analgesic, sedative, and anxiolytic properties. Pharmacological studies demonstrated that $L$-THP is an antagonist of dopamine (DA) D1 and D2 receptors [5]. The DA system has been reported to play an important role in drug addiction. As a nonselective DA antagonist, $L$-THP has recently emerged as a promising agent for treating addiction to many types of drugs, including cocaine $[6,7]$, 
methamphetamine [8], and oxycodone [9]. In our previous study, $L$-THP showed a potential therapeutic effect on KET addiction [10]. Moreover, $L$-THP is safe and effective, with no obvious side effects. However, the pharmacokinetic effects of $L$-THP on KET remain unclear.

In this study, a sensitive ultraperformance liquid chromatography tandem mass spectrometry (UPLC-MS/MS) method was developed to determine KET and NK concentrations in rat plasma. The pharmacokinetic effects of $L$-THP on KET were investigated to explore the anti-KET addiction mechanism of $L$-THP.

\section{Materials and Method}

2.1. Chemicals and Reagents. All reagents and solvents were of analytical grade. KET (purity $>98 \%$, Figure 1(a)), NK (purity $>98 \%$, Figure 1(b)), and chlorpheniramine maleate (Chlor-Trimeton; IS, purity $>98 \%$, Figure 1(c)) standards were purchased from Chinese Pharmaceutical and Biological Products Institute (Beijing, China). KET hydrochloride was purchased from Hengrui Pharmaceutical Factory (Jiangxi, China). L-THP (99.00\%) and UPLC-grade acetonitrile were purchased from Sigma-Aldrich Inc. (St. Louis, MO, USA). Male Sprague-Dawley rats (220-250 g) were purchased from Academy of Military Medical Science (AMMS, Beijing, China).

2.2. Instrumentation and Conditions. A UPLC-MS/MS system with TSQ Quantum (Waters, Xevo, TQS, USA) and Access Masslynx 4.1 software (Waters Corp.) was used to acquire the data and control instrument. Chromatographic separation was performed on a UPLC BEH C18 column $(2.1 \mathrm{~mm} \times 50 \mathrm{~mm}, 1.7 \mu \mathrm{m})$ (Waters, Milford, MA USA) thermostatted at $25^{\circ} \mathrm{C}$ with a mobile phase composed of acetonitrile-water with $0.1 \%$ methanoic acid $(80: 20, v / v)$ at a flow rate of $0.2 \mathrm{~mL} / \mathrm{min}$. Before use, the mobile phase was filtered through a $0.45 \mu \mathrm{m}$ nylon membrane filter. The injection volume was $10 \mu \mathrm{L}$, and the analysis time was 5 minutes for each sample.

Nitrogen was used as a drying gas for solvent evaporation $(40 \mathrm{~L} / \mathrm{h})$. The ion monitoring conditions were as follows: source temperature, $300^{\circ} \mathrm{C}$ and desolvation temperature, $110^{\circ} \mathrm{C}$. The collision energy was $25 \mathrm{eV}$ for $\mathrm{KET}, 19 \mathrm{eV}$ for $\mathrm{NK}$, and $25 \mathrm{eV}$ for Chlor-Trimeton (IS). Quantification was performed using multiple reaction monitoring (MRM), with modes of $\mathrm{m} / \mathrm{z} 238.1 \rightarrow \mathrm{m} / \mathrm{z} 179.1$ for KET, $\mathrm{m} / \mathrm{z} 224.1 \rightarrow \mathrm{m} / \mathrm{z}$ 207.1 for $\mathrm{NK}$, and $\mathrm{m} / \mathrm{z} 275 \rightarrow \mathrm{m} / \mathrm{z} 230$ for Chlor-Trimeton (IS), Figure 2. The MRM parameters for KET, NK, and Chlor-Trimeton (IS) are presented in Table 1.

2.3. Preparation of Stock Solution, Calibration Standards, and Quality Control of Samples. KET, NK, and Chlor-Trimeton (IS) stock solutions were prepared in acetonitrile at a concentration of $1.0 \mathrm{mg} / \mathrm{mL}$. Working solutions for calibration and controls were obtained by diluting the stock solutions with acetonitrile. All solutions were stored at $4^{\circ} \mathrm{C}$ until further use. Calibration standard samples were prepared by adding the KET and NK standards in various concentrations to blank rat plasma. Calibration plots were created for KET and $\mathrm{NK}$ in rat plasma (amounts of 2.5, 10, 12.5, 50, 100,
250, and $500 \mathrm{ng} / \mathrm{mL}$ ). Quality control (QC) samples were prepared in the same manner as the calibration standards which is of low-quality control (LQC, $5 \mathrm{ng} / \mathrm{mL}$ ), mediumquality control (MQC, $50 \mathrm{ng} / \mathrm{mL}$ ), and high-quality control (HQC, $500 \mathrm{ng} / \mathrm{mL}$ ), respectively.

2.4. Plasma Sample Preparation. Plasma sample aliquots $(100 \mu \mathrm{L})$ were mixed with $200 \mu \mathrm{L}$ of distilled water containing $50 \mathrm{ng}$ of Chlor-Trimeton (IS) in $10 \mathrm{~mL}$ centrifuge tubes, and $\mathrm{NaOH}(2 \mathrm{M})$ was added to adjust to $\mathrm{pH} 12$. The samples were then extracted twice with $5 \mathrm{~mL}$ of diethyl ether, vortex mixed for 3 minutes. After centrifugation at $3000 \mathrm{rpm}$ (1006.2 g) for 10 minutes, the organic phase was separated and evaporated in a water bath at $40^{\circ} \mathrm{C}$. Dried extracts were redissolved with $100 \mu \mathrm{L}$ of mobile phase and filtered through microfiltration membranes. Then, $10 \mu \mathrm{L}$ aliquots of the samples were injected into the UPLC-MS/MS system for analysis.

\subsection{Method Validation}

2.5.1. Precision and Accuracy. The LLOQ concentration $(2.5 \mathrm{ng} / \mathrm{mL})$ and three QC sample concentrations (5, 50, and $500 \mathrm{ng} / \mathrm{mL}$ ) of KET and NK were used to evaluate the assay precision and accuracy. The intraday precision was calculated for all three concentrations using six determinations per concentration (on the same day), while the interday precision was measured over 3 consecutive days. The accepted criteria for each sample were that the precision and accuracy should not exceed $10 \%$. The precision was expressed as the relative standard deviation (RSD) and the accuracy as the relative error (RE) [11].

2.5.2. Extraction Recovery and Matrix Effect. The extraction recoveries of KET and $\mathrm{NK}$ were determined for the three QC sample concentrations $(5,50$, and $500 \mathrm{ng} / \mathrm{mL})$. The recoveries were calculated by comparing the observed peak area ratios of biological samples to those of unprocessed standard solutions at the same concentrations [12]. The matrix effects in the approach were evaluated by comparing the peak areas of the compounds in the postextraction spiked samples with those of the standard solutions [11].

2.5.3. Stability. The stabilities of KET and NK in rat plasma were evaluated at three different QC concentrations using six replicates under two conditions, including at $25^{\circ} \mathrm{C}$ for $12 \mathrm{~h}$, and three freeze and thaw cycles. Unextracted QC samples of the two compounds at 5,50 , and $500 \mathrm{ng} / \mathrm{mL}$ concentrations were kept at $25^{\circ} \mathrm{C}$ for $12 \mathrm{~h}$ to determine the stability of the compounds in rat plasma. The samples were processed and analyzed, and then, the concentrations were compared with the nominal values of the QC samples. The stabilities of the plasma samples after three freeze and thaw cycles were determined. In each cycle, the QC samples were stored at $-20^{\circ} \mathrm{C}$ for $24 \mathrm{~h}$ and thawed unassisted at room temperature. When completely thawed, the samples were refrozen with $24 \mathrm{~h}$. The cycle was repeated three times, and the samples were analyzed after the third cycle. Stability was assessed by comparing the mean concentration of the stored QC samples with the mean concentration of freshly prepared QC samples [11]. 
<smiles>CNC1(c2ccccc2Cl)CCCCC1=O</smiles>

(a)<smiles>CC1(Nc2ccccc2Cl)CCCCC1=O</smiles>

(b)<smiles>COc1cc2c(cc1OC)CN1CCN(C2)Cc2c(OC)ccc(OC)c21</smiles>

(c)

Figure 1: Molecular structure of ketamine (KET) (a), norketamine (NK) (b), and chlorpheniramine maleate (Chlor-Trimeton, IS) (c).

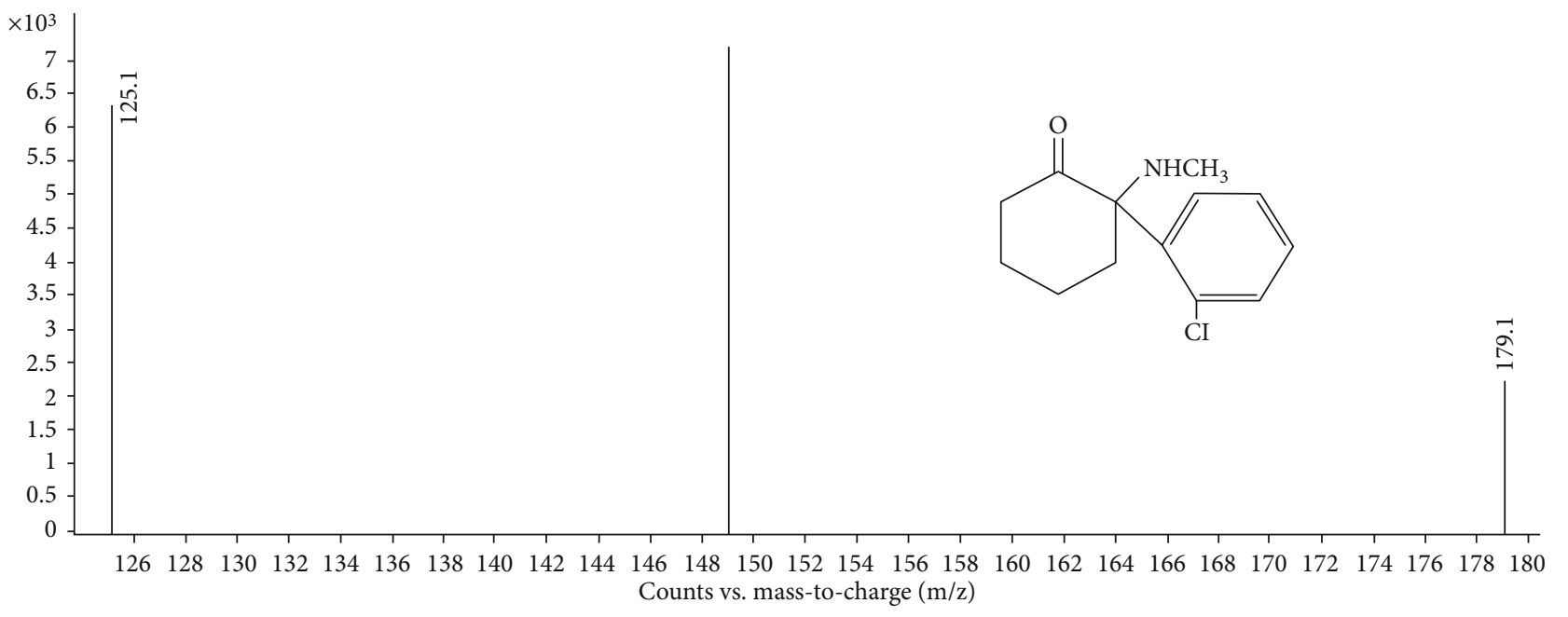

(a)

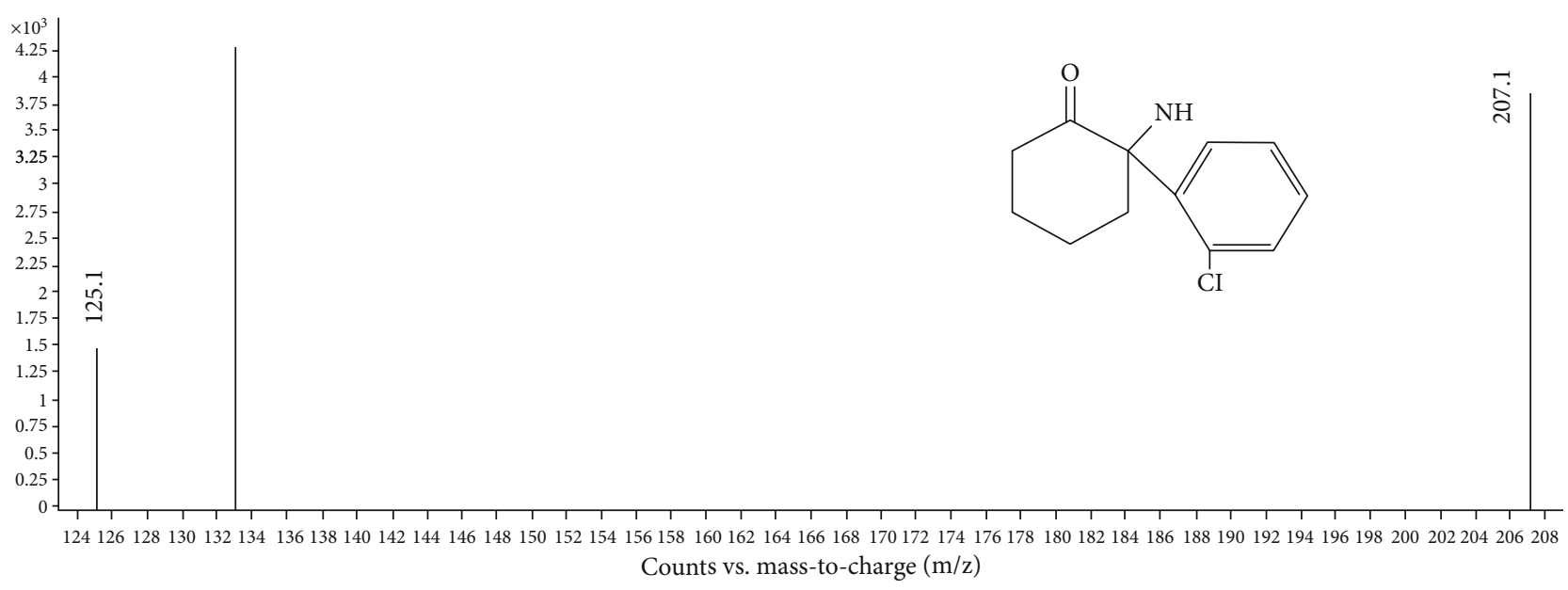

(b)

Figure 2: Second level mass spectrum of KET (a) and NK (b).

2.6. Animal and Pharmacokinetic Study. The SpragueDawley rats (220-250 g) were randomly assigned to one of the three groups: the saline group, KET group, or KET combined with $L$-THP group (each, $n=6$ ). KET and $L$-THP were dissolved in saline. Gastric gavage was used for administration of $20 \mathrm{~mL} / \mathrm{kg}$ saline to the saline group, $100 \mathrm{mg} / \mathrm{kg} \mathrm{KET}$ to the KET group [13], and $100 \mathrm{mg} / \mathrm{kg} \mathrm{KET} \mathrm{and} 40 \mathrm{mg} / \mathrm{kg}$ $L$-THP to the KET combined with $L$-THP group. Blood 
TABLE 1: MRM parameters for drugs and IS.

\begin{tabular}{lcccc}
\hline Drugs & $\begin{array}{c}\text { Parent } \\
\text { ion }\end{array}$ & $\begin{array}{c}\text { The cluster } \\
\text { voltage }(\mathrm{V})\end{array}$ & $\begin{array}{c}\text { Daughter } \\
\text { ion }\end{array}$ & $\begin{array}{c}\text { Collision energy } \\
(\mathrm{eV})\end{array}$ \\
\hline \multirow{2}{*}{ KET } & 238.1 & 40 & $179.1^{*}$ & 25 \\
& & & 125.1 & 40 \\
\multirow{2}{*}{ NK } & 224.1 & 40 & $207.1^{*}$ & 19 \\
& & & 125.1 & 32 \\
IS & 275 & & $230^{*}$ & 25 \\
\hline
\end{tabular}

${ }^{*}$ Quantitative ion.

samples $(0.5 \mathrm{~mL})$ were withdrawn from the orbital vein at $0.083,0.25,0.5,0.75,1,1.5,2,3,4$, and 5 hours after drug administration. The doses of the drugs and sampling intervals were chosen based on previous reports $[13,14]$. All samples were collected into heparinized tubes and then centrifuged at $13,000 \mathrm{rpm}(14900 \mathrm{~g})$ for 10 minutes at $4^{\circ} \mathrm{C}$. The plasma was transferred to fresh tubes and stored at $-80^{\circ} \mathrm{C}$ prior to analysis.

2.7. Pharmacokinetics Parameters and Statistical Analysis. The plasma concentration versus time data for each rat was analyzed using DAS (Drug and Statistics) software (version 2.0, China Pharmaceutical University). The area under the curve from time zero until infinity $\left(\mathrm{AUC}_{0-\infty}\right)$, distribution phase half-life $\left(t_{1 / 2 \alpha}\right)$, elimination phase half-life $\left(t_{1 / 2 \beta}\right)$, maximum plasma concentration $\left(C_{\max }\right)$, absorption phase halflife $\left(t_{1 / 2 \mathrm{a}}\right)$, time of maximal plasma concentration $\left(t_{\max }\right)$, and clearance (CL) were estimated using one- and twocompartment model calculations performed with DAS software. Comparisons between parameters were performed using $t$-test. In all analyses, $P<0.05$ (two tailed) was taken to indicate statistical significance.

\section{Results}

\subsection{UPLC-MS/MS Method Verification}

3.1.1. Selectivity. Typical UPLC-MS/MS chromatograms of blank plasma and plasma samples collected from the orbital vein of rats are shown in Figure 3, demonstrating that there were no major interference from endogenous substances in the analysis of the compounds, and good selectivity was achieved.

3.1.2. Linearity and Sensitivity. Calibration curves of KET and $\mathrm{NK}$ in rat plasma indicated good linearity over the concentration range $2.5-500 \mathrm{ng} / \mathrm{mL}$. The regression equations were as follows: $Y_{1}=0.0009 X_{1}+0.0034, r=0.9995$ and $Y_{2}=0.0009 X_{2}-0.0015, r=0.9998$. $Y_{1}$ represents the ratio of the peak intensity of KET to the internal standard, and $X_{1}$ represents the concentration of KET in plasma; $Y_{2}$ represents the ratio of the peak intensity of NK to the internal standard, and $X_{2}$ represents the concentration of $\mathrm{NK}$ in plasma. The assay had an LLOQ of $2.5 \mathrm{ng} / \mathrm{mL}$ for KET and NK in rat plasma samples. The results are shown in Table 2.

3.1.3. Precision and Accuracy. Table 3 summarizes the KET and NK analysis results. The RSDs for the intraday and inter- day precision at three concentration levels of KET were below $3.34 \%$ and $4.31 \%$, respectively. The accuracy of KET was in the range of $-8.11 \%$ to $-1.41 \%$. While the RSDs for the intraday and interday precisions of NK were below $5.75 \%$ and $6.53 \%$, respectively. The accuracy of NK was in the range of $-9.28 \%$ to $-6.07 \%$. These results indicated that the precision and accuracy of the established UPLC-MS/MS method were satisfactory for KET and NK.

3.1.4. Extraction Recovery and Matrix Effect. The extraction recoveries of KET were no less than $81.23 \pm 3.45 \%$, while the extraction recoveries of NK were no less than $80.42 \pm$ $4.57 \%$ (Table 3 ), suggesting that the precision and accuracy of this method were acceptable. The matrix effects of KET at the three QC levels ranged from $90.61 \pm 3.22 \%$ to 105.47 $\pm 2.89 \%$, while the matrix effects of NK ranged from 91.38 $\pm 2.56 \%$ to $104.35 \pm 3.21 \%$, which indicated that the matrix effect was negligible.

3.1.5. Stability. The results for the room temperature and freeze-thaw stability are shown in Table 4. There was no major degradation of the two compounds under the different storage conditions.

3.2. Pharmacokinetic Study. The mean plasma concentration-time curves of KET and NK are presented in Figure 4. The pharmacokinetic parameters for KET and NK are listed in Tables 5 and 6 . When administered intragastrically to rats, KET was absorbed rapidly; with a short $t_{\max }$ of $15.0 \mathrm{~min}$. Concomitant intake of L-THP resulted in a significant increase in the plasma KET $C_{\max }$ and AUC. The mean KET $C_{\max }$ value increased from $3.63 \pm 2.40 \mu \mathrm{g} / \mathrm{mL}$ to $4.50 \pm 1.31$ $\mu \mathrm{g} / \mathrm{mL}(P<0.05)$ and the mean AUC from $358.75 \pm 3.21$ $\mu \mathrm{g} \cdot \mathrm{min} / \mathrm{mL}$ to $512.75 \pm 4.70 \mu \mathrm{g} \cdot \mathrm{min} / \mathrm{mL}(P<0.05)$. Furthermore, when L-THP was coadministered, the plasma NK $C_{\max }$ and AUC increased from $4.45 \pm 1.71 \mu \mathrm{g} / \mathrm{mL}$ to $6.44 \pm 2.62$ $\mu \mathrm{g} / \mathrm{mL}(P<0.05)$, and from $803.42 \pm 3.70 \mu \mathrm{g} \cdot \mathrm{min} / \mathrm{mL}$ to $1176.33 \pm 3.80 \mu \mathrm{g} \cdot \mathrm{min} / \mathrm{mL}$, respectively $(P<0.05)$.

\section{Discussion}

A sensitive, rapid, and selective UPLC-MS/MS method was established in the present study to determine the concentrations of KET and NK in rat plasma. The method was used successfully to study the pharmacokinetic effects of $L$-THP on KET in rat plasma.

As a DA receptor antagonist, $L$-THP has therapeutic potential in the treatment of addiction to many drugs, including cocaine [15], heroin [16], and methamphetamine [17]. In our previous study, $L$-THP showed a potential therapeutic effect on KET addiction [10]. However, the pharmacokinetic effects of ${ }_{L}$-THP on KET remained unclear. Chen et al. studied the pharmacokinetics interaction between KET and rhynchophylline using UPLC-MS/MS. They found that there was a reciprocal inhibition between KET and rhynchophylline [18].

When various drugs are used together, attention must be paid to the interactions between them. Chinese herbal medicine can induce or inhibit hepatic drug-metabolizing 


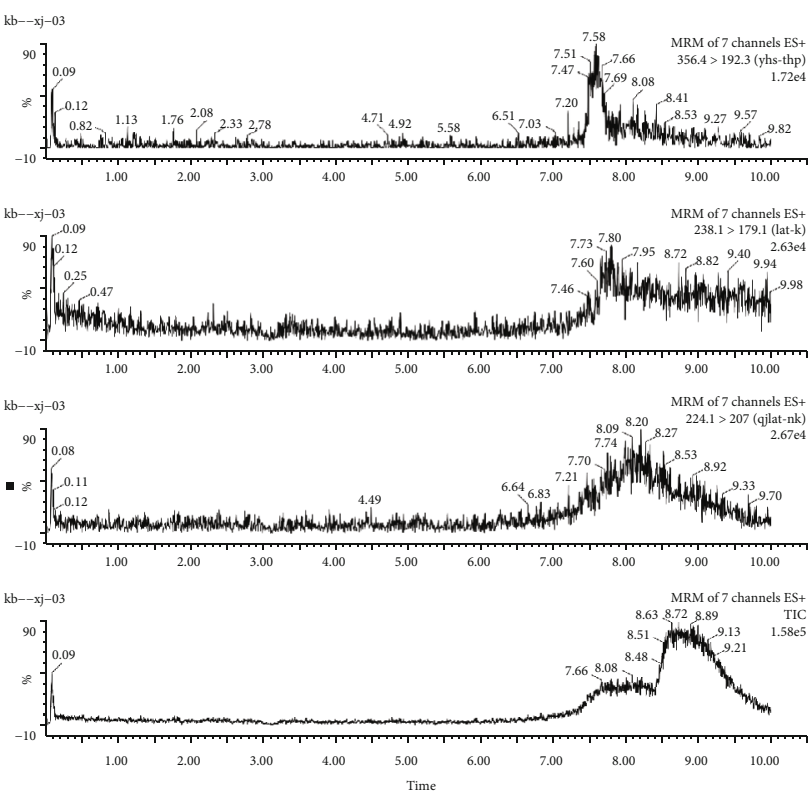

(a)
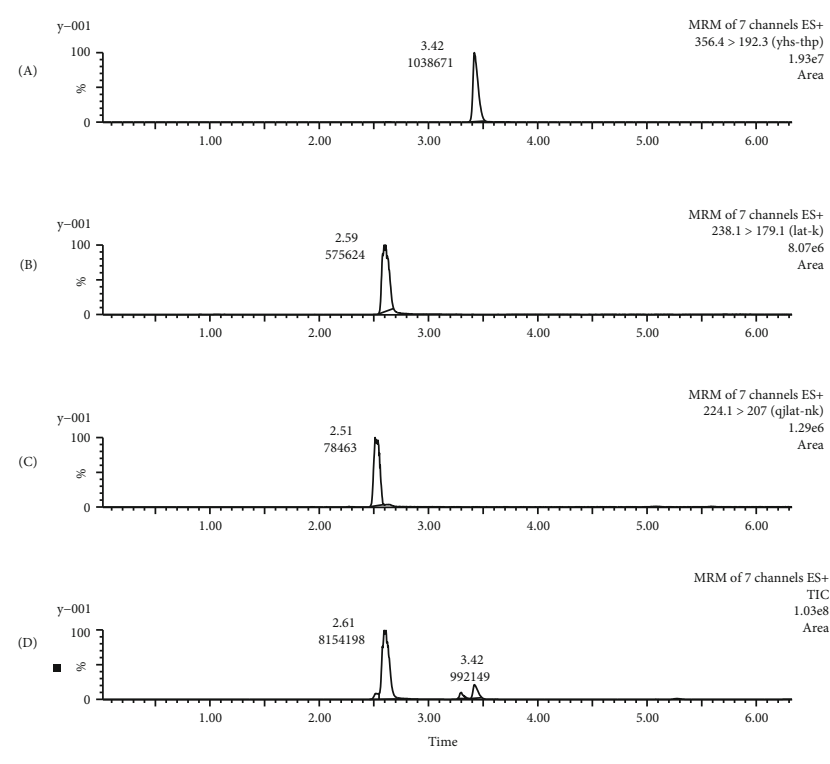

(b)

FIGURE 3: Representative ultraperformance liquid chromatography tandem mass spectrometry (UPLC-MS/MS) chromatograms: (a) blank plasma and (b) a rat plasma sample after intragastric administration of (A) L-tetrahydropalmatine (L-THP), (B) ketamine (KET), and (C) norketamine (NK).

TABLE 2: Calibration equation and limits of detection of KET and NK in rat plasma.

\begin{tabular}{cccccc}
\hline & Drugs & Calibration equation & LLOQ $(\mathrm{ng} / \mathrm{mL})$ & Correlation Coefficient $(r)$ & Linearity range $(\mathrm{ng} / \mathrm{mL})$ \\
\hline \multirow{2}{*}{ Plasma } & KET & $Y_{1}=0.0009 X_{1}+0.0034$ & 2.5 & 0.9995 & $2.5-500$ \\
& $\mathrm{NK}$ & $Y_{2}=0.0009 X_{2}-0.0015$ & 2.5 & 0.9998 & $2.5-500$ \\
\hline
\end{tabular}

TABLe 3: Precision, accuracy, recovery, and matrix effect of KET and NK in rat plasma $(n=6)$.

\begin{tabular}{|c|c|c|c|c|c|c|c|}
\hline \multirow{2}{*}{ Compound } & \multirow{2}{*}{ Concentration ng/mL) } & \multicolumn{2}{|c|}{ Precision (RSD \%) } & \multicolumn{2}{|c|}{ Accuracy (RE\%) } & \multirow{2}{*}{ Extraction recovery $(\%)$} & \multirow{2}{*}{ Matrix effect (\%) } \\
\hline & & Intraday & Interday & Intraday & Interday & & \\
\hline \multirow{4}{*}{ KET } & LLOQ (2.5) & 3.15 & 2.95 & -4.31 & -5.54 & - & - \\
\hline & LQC (5) & 2.72 & 4.31 & -1.41 & -8.11 & $81.23 \pm 3.45$ & $90.61 \pm 3.22$ \\
\hline & MQC (50) & 3.34 & 2.60 & -6.43 & -5.23 & $83.78 \pm 4.87$ & $91.78 \pm 4.76$ \\
\hline & HQC (500) & 2.62 & 2.82 & -5.92 & -6.51 & $87.56 \pm 6.92$ & $105.47 \pm 2.89$ \\
\hline \multirow{4}{*}{ NK } & LLOQ (2.5) & 4.38 & 5.12 & -6.27 & -7.11 & - & - \\
\hline & LQC (5) & 5.75 & 6.53 & -8.46 & -7.02 & $85.47 \pm 2.63$ & $91.38 \pm 2.56$ \\
\hline & MQC (50) & 3.71 & 4.41 & -7.43 & -9.28 & $80.42 \pm 4.57$ & $93.44 \pm 4.63$ \\
\hline & HQC (500) & 2.50 & 2.66 & -6.28 & -6.07 & $82.36 \pm 3.66$ & $104.35 \pm 3.21$ \\
\hline
\end{tabular}

RSD: relative standard deviation; RE: relative error; LLOQ: lower limit of quantitation; LQC: low-quality control; MQC: medium-quality control; HQC: highquality control.

enzymes (CYP450), so there may be metabolic interactions between these agents and Western medicines [19].

Chinese medicine can inhibit or induce enzymes, such as CYP450, drug transport proteins, and UDP-glucuronosyl transferase (UGT), thereby influencing the concentrations of medications in blood, body fluids, and tissues, which would in turn alter the pharmacokinetic parameters [18-21].
The primary pharmacokinetic parameters of KET were as follows: $C_{\max }, \quad 3.63 \pm 2.40 \mu \mathrm{g} / \mathrm{mL} ; \quad$ AUC, $\quad 358.75 \pm 3.21$ $\mu \mathrm{g} \cdot \mathrm{min} / \mathrm{mL} ; t_{\max }, 15.0 \pm 1.20 \mathrm{~min} ; t_{1 / 2}, 31.42 \pm 1.59 \mathrm{~min}$; and CL, $3.36 \pm 1.01 \mathrm{~L} / \mathrm{h} / \mathrm{kg}$. Compared to the KET alone group, there were significant differences in $C_{\max }, \mathrm{AUC}$, and $t_{\max }$ after administration of KET combined with $L$-THP. $C_{\max }$, AUC, and $t_{\max }$ were increased by $1.42-, 1.24-$, and 
TABLE 4: Stability of KET and NK in rat plasma at room temperature or freeze thaw.

\begin{tabular}{|c|c|c|c|c|c|}
\hline Compound & Concentration (ng/mL) & $12 \mathrm{~h}$ measured $\mathrm{C}(\mathrm{ng} / \mathrm{mL})$ & RSD (\%) & Freeze thaw & RSD (\%) \\
\hline \multirow{3}{*}{ KET } & LQC (5) & $4.71 \pm 0.02$ & 3.96 & $4.79 \pm 0.23$ & 5.28 \\
\hline & MQC (50) & $48.21 \pm 1.23$ & 5.98 & $48.99 \pm 1.54$ & 2.31 \\
\hline & HQC (500) & $490.31 \pm 1.08$ & 2.13 & $489.30 \pm 2.41$ & 3.56 \\
\hline \multirow{3}{*}{ NK } & LQC (5) & $4.86 \pm 2.05$ & 3.50 & $4.81 \pm 0.34$ & 4.54 \\
\hline & MQC (50) & $48.52 \pm 1.06$ & 5.29 & $47.63 \pm 1.67$ & 3.56 \\
\hline & HQC (500) & $495.81 \pm 1.08$ & 2.81 & $492.42 \pm 3.78$ & 4.98 \\
\hline
\end{tabular}

LQC: low-quality control; MQC: medium-quality control; HQC: high-quality control.

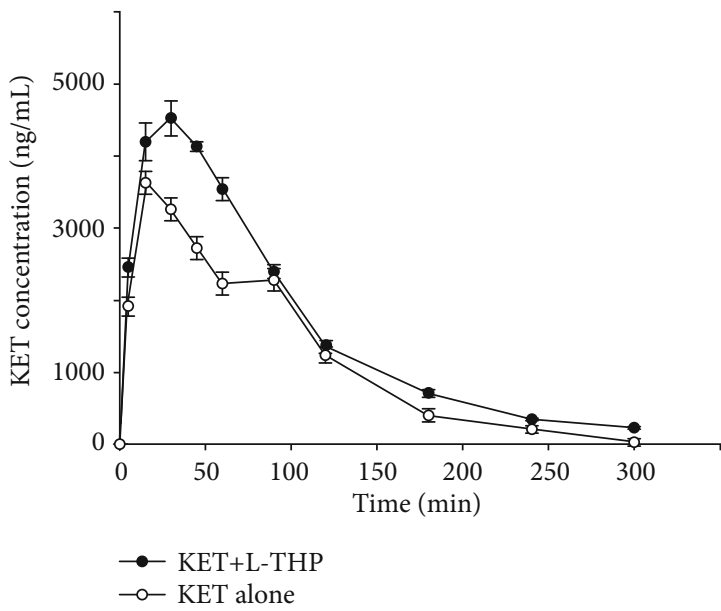

(a)

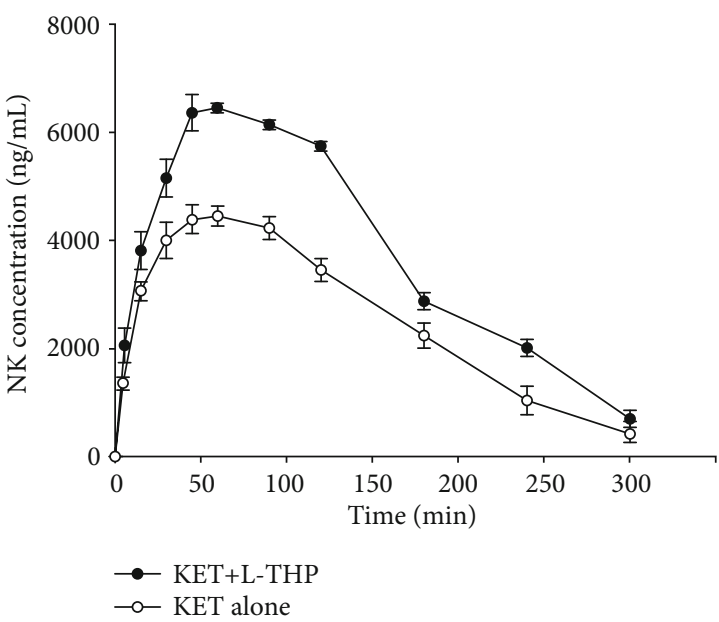

(b)

FIGURE 4: Mean (a) KET and (b) NK concentration-time curves of plasma levels after administration of KET alone and in combination with $L$-THP $(n=6)$.

TABLE 5: Pharmacokinetic parameters of KET after administration of KET alone and in combination with $L$-THP $(n=6)$.

\begin{tabular}{lccccc}
\hline Parameters & Unit & KET group & Parameters & Unit & KET+L-THP group \\
\hline AUC $_{0-\infty}$ & $\mu \mathrm{g} \cdot \mathrm{min} / \mathrm{mL}$ & $358.75 \pm 3.21$ & $\mathrm{AUC}_{0-\infty}$ & $\mu \mathrm{g} \cdot \mathrm{min} / \mathrm{mL}$ & $512.75 \pm 4.70^{*}$ \\
$t_{1 / 2}$ & $\min$ & $31.42 \pm 1.59$ & $t_{1 / 2 \alpha}$ & $\min$ & $39.34 \pm 1.12$ \\
$\mathrm{CL}$ & $\mathrm{L} / \mathrm{h} / \mathrm{kg}$ & $3.36 \pm 1.01$ & $t_{1 / 2 \beta}$ & $\min$ & $69.32 \pm 2.0$ \\
$C_{\max }$ & $\mu \mathrm{g} / \mathrm{mL}$ & $3.63 \pm 2.40$ & $\mathrm{CL}$ & $\mathrm{L} / \mathrm{h} / \mathrm{kg}$ & $2.34 \pm 1.62$ \\
$t_{\max }$ & $\min$ & $15.0 \pm 1.20$ & $C_{\max }$ & $\mu \mathrm{g} / \mathrm{mL}$ & $4.50 \pm 1.31^{*}$ \\
& & - & $t_{1 / 2 \mathrm{a}}$ & $\min$ & $11.27 \pm 2.33$ \\
& & - & $t_{\max }$ & $\min$ & $30.0 \pm 1.50^{*}$ \\
\hline
\end{tabular}

Values represent the mean \pm SEM of six rats/group. Through gastric gavage, rats were administered KET alone $(100 \mathrm{mg} / \mathrm{kg})$ or in combination with oral $L$-THP $(40 \mathrm{mg} / \mathrm{kg})$. *Significantly different from KET-treated rats $(P<0.05)$.

2.0-fold, respectively, after combined use, suggesting that $L^{-}$ THP may increase the absorption of KET. The primary pharmacokinetic parameters of NK were as follows: AUC, $803.42 \pm 3.70 \mu \mathrm{g} \cdot \mathrm{min} / \mathrm{mL}$ and $C_{\max }, \quad 4.45 \pm 1.71 \mu \mathrm{g} / \mathrm{mL}$. Compared to the KET alone group, there were significant differences in AUC and $C_{\max }$ after administration of KET combined with $L$-THP. AUC and $C_{\max }$ were increased by 1.46- and 1.44-fold, respectively, after combined use, suggest- ing that $L$-THP may promote the metabolism of KET. Peltoniemi et al. reported that KET undergoes oxidative metabolism, mainly to NK, by CYP4503A and CYP2B6 [22]. Hijazi and Boulieu reported that the subtypes of CYP450 (CYP2C9, CYP2B, and CYP3A) participated in $N$ demethylation of KET in the rat liver and that KET may have an effect on the enzyme substrate in vivo [23]. Therefore, $L^{-}$ THP may promote the expression of CYP2C9, CYP2B6, 
TABLE 6: Pharmacokinetic parameters of NK after administration of KET alone and in combination with $L$-THP $(n=6)$.

\begin{tabular}{lccc}
\hline Parameters & Unit & KET group & KET $+L$-THP group \\
\hline AUC & $\mu \mathrm{g} \cdot \mathrm{min} / \mathrm{mL}$ & $803.42 \pm 3.70$ & $1176.33 \pm 3.80^{*}$ \\
$t_{1 / 2}$ & $\mathrm{Min}^{-1}$ & $45.36 \pm 1.59$ & $47.52 \pm 2.13$ \\
$\mathrm{CL}$ & $\mathrm{L} \cdot \mathrm{kg} / \mathrm{h}$ & $1.5 \pm 0.61$ & $1.02 \pm 0.50$ \\
$C_{\max }$ & $\mu \mathrm{g} / \mathrm{mL}$ & $4.45 \pm 1.71$ & $6.44 \pm 2.62^{*}$ \\
$k_{\mathrm{a}}$ & & $0.017 \pm 1.05$ & $0.016 \pm 1.20$ \\
\hline
\end{tabular}

Values represent the mean \pm SEM of six rats/group. Rats were treated with oral KET $(100 \mathrm{mg} / \mathrm{kg})$ alone or in combination with L-THP p.o. $(40 \mathrm{mg} / \mathrm{kg}) .{ }^{*}$ Significantly different from KET-treated rats $(P<0.05)$.

and CYP3A4, thereby accelerating the metabolism of KET, as indicated by our results. However, further studies are needed to verify the interaction of KET with $L$-THP.

\section{Conclusion}

A UPLC-MS/MS method was established in the present study to investigate the pharmacokinetic effects of $L$-THP on KET and NK. The results showed that $L$-THP can increase the absorption and metabolism of KET, possibly through effects on hepatic enzymes. However, further studies are needed to determine the mechanisms underlying the putative interactions.

\section{Data Availability}

The data used to support the findings of this study are available from the corresponding author upon request.

\section{Conflicts of Interest}

The authors declare that they have no conflicts of interest.

\section{Acknowledgments}

This work was supported by a grant from the Scientific and Technological Innovation Programs of Higher Education Institutions in Shanxi (No. 2017145), a grant from the Graduate Student Education Innovation Project in Shanxi Province (No. 2017BY074), and a grant from Startup Foundation for Doctors of Shanxi Medical University (No. BS201732) to Yan Du.

\section{References}

[1] World Health Organization, "Ketamine expert peer review on critical review report (2)," in 35th Expert Committee on Drug Dependence.June, pp. 4-8, WHO, Hammamet, Tunisia, 2012.

[2] D. A. Haas and D. G. Harper, "Ketamine: a review of its pharmacologic properties and use in ambulatory anesthesia," Anesthesia Progress, vol. 39, no. 3, pp. 61-68, 1992.

[3] J. White and C. Ryan, "Pharmacological properties of ketamine," Drug and Alcohol Review, vol. 15, no. 2, pp. 145-155, 1996.

[4] G. S. Ding, "Important Chinese herbal remedies," Clinical Therapeutics, vol. 9, no. 4, pp. 345-357, 1987.
[5] H. Chu, G. Jin, E. Friedman, and X. Zhen, "Recent Development in Studies of Tetrahydroprotoberberines: Mechanism in Antinociception and Drug Addiction," Cellular and Molecular Neurobiology, vol. 28, no. 4, pp. 491-499, 2008.

[6] J. R. Mantsch, S.-J. Li, R. Risinger et al., "Levo-tetrahydropalmatine attenuates cocaine self-administration and cocaineinduced reinstatement in rats," Psychopharmacology, vol. 192, no. 4, pp. 581-591, 2007.

[7] J. R. Mantsch, S. Wisniewski, O. Vranjkovic et al., "Levo-tetrahydropalmatine attenuates cocaine self-administration under a progressive-ratio schedule and cocaine discrimination in rats," Pharmacology, Biochemistry, and Behavior, vol. 97, no. 2, pp. 310-316, 2010.

[8] N. Zhao, Y. Chen, J. Zhu et al., "Levo-tetrahydropalmatine attenuates the development and expression of methamphetamine-induced locomotor sensitization and the accompanying activation of ERK in the nucleus accumbens and caudate putamen in mice," Neuroscience, vol. 258, pp. 101-110, 2014.

[9] Y.-L. Liu, L.-D. Yan, P.-L. Zhou, C.-F. Wu, and Z.-H. Gong, "Levo-tetrahydropalmatine attenuates oxycodone-induced conditioned place preference in rats," European Journal of Pharmacology, vol. 602, no. 2-3, pp. 321-327, 2009.

[10] Y. Du, L. Du, J. Cao et al., "Levo-tetrahydropalmatine inhibits the acquisition of ketamine-induced conditioned place preference by regulating the expression of ERK and CREB phosphorylation in rats," Behavioural Brain Research, vol. 317, pp. 367-373, 2017.

[11] S. Xu, X. Qi, Y. Liu et al., "UPLC-MS/MS of Atractylenolide I, Atractylenolide II, Atractylenolide III, and Atractyloside A in Rat Plasma after Oral Administration of Raw and Wheat Bran-Processed Atractylodis Rhizoma," Molecules, vol. 23, no. 12, p. 3234, 2018.

[12] J. Cao, Y. Du, Y.-J. Wang et al., "Pharmacokinetics of Meperidine (Pethidine) in Rabbit Oral Fluid: Correlation With Plasma Concentrations After Controlled Administration," Pharmazie, vol. 73, no. 6, pp. 324-328, 2018.

[13] H. Z. Rofael and M. S. Abdel-Rahman, "The role of ketamine on plasma cocaine pharmacokinetics in rat," Toxicology Letters, vol. 129, no. 1-2, pp. 167-176, 2002.

[14] Z. Hong, G. Fan, Y. Chai, X. Yin, and Y. Wu, "Stereoselective pharmacokinetics of tetrahydropalmatine after oral administration of (-)-enantiomer and the racemate," Chirality, vol. 17, no. 5, pp. 293-296, 2005.

[15] J. B. Wang and J. R. Mantsch, "l-tetrahydropalamatine: a potential new medication for the treatment of cocaine addiction," Future Medicinal Chemistry, vol. 4, no. 2, pp. 177-186, 2012.

[16] Z. Yang, Y.-c. Shao, L. Shi-jiang et al., "Medication of $l$-tetrahydropalmatine significantly ameliorates opiate craving and increases the abstinence rate in heroin users: a pilot study," Acta Pharmacologica Sinica, vol. 29, no. 7, pp. 781-788, 2008.

[17] H.-L. Su, J. Zhu, Y.-J. Chen et al., "Roles of levotetrahydropalmatine in modulating methamphetamine reward behavior," Physiology \& Behavior, vol. 118, pp. 195200, 2013.

[18] L. Chen, W. You, D. Chen et al., "Pharmacokinetic Interaction Study of Ketamine and Rhynchophylline in Rat Plasma by Ultra-Performance Liquid Chromatography Tandem Mass Spectrometry," BioMed Research International, vol. 2018, Article ID 6562309, 8 pages, 2018. 
[19] H.-J. Cho and I.-S. Yoon, "Pharmacokinetic Interactions of Herbs with Cytochrome P450 and P-Glycoprotein," Evidence-Based Complementary and Alternative Medicine, vol. 2015, Article ID 736431, 10 pages, 2015.

[20] B. Li, B. Zhao, Y. Liu et al., "Herb-drug enzyme-mediated interactions and the associated experimental methods: a review," Journal of Traditional Chinese Medicine, vol. 36, no. 3, pp. 392-408, 2016.

[21] I.-S. Song, T. Y. Kong, H.-U. Jeong et al., "Evaluation of the transporter-mediated herb-drug interaction potential of DA9801, a standardized dioscorea extract for diabetic neuropathy, in human in vitro and rat in vivo," BMC Complementary and Alternative Medicine, vol. 14, no. 1, p. 251, 2014.

[22] M. A. Peltoniemi, N. M. Hagelberg, K. T. Olkkola, and T. I. Saari, "Ketamine: A Review of Clinical Pharmacokinetics and Pharmacodynamics in Anesthesia and Pain Therapy," Clinical Pharmacokinetics, vol. 55, no. 9, pp. 1059-1077, 2016.

[23] Y. Hijazi and R. Boulieu, "Contribution of CYP3A4, CYP2B6, and CYP2C9 Isoforms toN-Demethylation of Ketamine in Human Liver Microsomes," Drug Metabolism and Disposition, vol. 30, no. 7, pp. 853-858, 2002. 